\title{
BMJ Open Visibility of tobacco products and advertisement at the point of sale: a systematic audit of retailers in Amsterdam
}

\author{
Paulien A W Nuyts, ${ }^{1}$ Mirte A G Kuipers, ${ }^{1}$ Alp Cakir, ${ }^{2}$ Marc C Willemsen, ${ }^{3,4}$ \\ Eleonore M Veldhuizen, ${ }^{2}$ Anton E Kunst ${ }^{1}$
}

To cite: Nuyts PAW, Kuipers MAG, Cakir A, et al. Visibility of tobacco products and advertisement at the point of sale: a systematic audit of retailers in Amsterdam. BMJ Open 2018;8:e022017. doi:10.1136/ bmjopen-2018-022017

- Prepublication history and additional material for this paper are available online. To view these files, please visit the journal online (http://dx.doi. org/10.1136/bmjopen-2018022017).

Received 30 January 2018 Revised 7 May 2018 Accepted 18 September 2018

Check for updates

(c) Author(s) (or their employer(s)) 2018. Re-use permitted under CC BY-NC. No commercial re-use. See rights and permissions. Published by BMJ.

${ }^{1}$ Department of Public Health, Amsterdam UMC, University of Amsterdam, Amsterdam, The Netherlands

${ }^{2}$ Department of Human Geography, Planning and International Development Studies, University of Amsterdam, Amsterdam, The Netherlands

${ }^{3}$ Department of Health Promotion, Maastricht University (CAPHRI), Maastricht, The

Netherlands

${ }^{4}$ Netherlands Expertise Center for Tobacco Control (NET), Trimbos Instituut, Utrecht, The Netherlands

Correspondence to

Paulien A W Nuyts;

p.a.nuyts@amc.uva.nl

\section{ABSTRACT}

Objectives Visibility of tobacco products at the point of sale $(\mathrm{PoS})$, in settings where open display of tobacco is allowed, is one of the last remaining ways in which the tobacco industry can legally promote their products. The aim of this study was to map the visibility of tobacco products and advertisement both inside and outside retailers, among different types of retailers.

Setting The study was conducted in two districts in Amsterdam, the Netherlands.

Participants All potential tobacco retailers were visited within the districts, and were mapped using Global Positioning System (GPS) coordinates.

Intervention Observational data was collected for each tobacco retailer using a checklist with characteristics of the internal and external visibility of tobacco products and advertisement. Retailers were categorised into supermarkets, hospitality industry, tobacconists and 'other retailers' (convenience stores, office supply stores, gas stations, drug stores and telephone communication stores). Data were collected in April-May 2017.

Results Eighty-two tobacco retailers were identified. Among all retailers, $52.4 \%$ had external and $91.5 \%$ internal visibility of tobacco products. Tobacconists had the highest level of internal and external visibility of tobacco products (both 100\%), followed by 'other retailers' (100\% and $56 \%$ respectively) and supermarkets $(79 \%$ and $47 \%$, respectively). Retailers in the hospitality industry had low external visibility (28\%), but high internal visibility (90\%), as $83 \%$ sold tobacco through vending machines.

Conclusion Visibility of tobacco products was high among all types of retailers, including those previous studies show are commonly visited by youth.

\section{INTRODUCTION}

Over the last decades, European countries have implemented many tobacco control policies to reduce smoking-related mortality. ${ }^{1}$ Even though tobacco advertisement for television, radio and print media has been widely banned since the $1990 \mathrm{~s},{ }^{2}$ the prohibition of tobacco marketing in the form of product visibility at the point of sale ( $\mathrm{PoS})$ has not been addressed at large. ${ }^{13}$ Visibility
Strengths and limitations of this study

- This is the first study to map detailed information on the internal and external visibility of tobacco products and advertisement among different types of retailers in continental Europe.

- An observation checklist to examine the visibility of tobacco products and advertisement was developed and can be applied in other countries.

- All data were systematically collected, minimising the risk that relevant tobacco retailers were missed.

- This study may be limited in its generalisability to other countries, due to the specific geographical area that was covered.

of tobacco products at the PoS has therefore become one of the last remaining ways for the tobacco industry to promote their products. ${ }^{4}$ Tobacco products can be made more visible through attractive pack designs, logos and shapes, and by strategically placing the packs within the customer's view (eg, at eye-level). ${ }^{4}$ Some retailers receive financial incentives from tobacco manufacturers to increase visibility by 'prime product placement'.

Exposure to tobacco at the PoS increases the risk of adolescent smoking uptake. ${ }^{6-9}$ An increase in the susceptibility of smoking uptake may be caused by PoS tobacco promotion which increases perceived attractiveness of smoking and brand awareness. ${ }^{8}$ High visibility of tobacco is likely to normalise smoking, as it supports a norm in which purchasing and using tobacco is accepted..$^{10}$ In the UK, around $80 \%$ of youth noticed tobacco displays at the PoS. ${ }^{69}$ The adverse impact of visible tobacco displays may be substantial, as a 2013 study in Scotland, conducted before the implementation of a PoS display ban, found that $52 \%$ of retailers had tobacco displays that were visible from the public footway outside the store, $69 \%$ of displays were visible from 
the main entrance, and $98 \%$ of the displays were placed at eye-level. ${ }^{6}$

Several European countries have implemented bans on PoS tobacco displays, including Iceland, Ireland, Finland, the UK, Hungary, Croatia and Norway. ${ }^{11}$ Yet, more than three quarters of European countries have not taken measures to limit exposure to tobacco PoS displays. Evidence for the effectiveness of PoS display bans is not conclusive, but bans have been associated with reduced exposure to tobacco marketing, ${ }^{12}$ reduced smoking prevalence among adolescents ${ }^{13}$ and denormalisation of smoking. ${ }^{14}$

Identifying among which retailers visibility is highest helps to estimate where and how a POS display ban should be implemented in order to have a maximal effect on visibility. Although a study in Scotland assessed the visibility of tobacco products, ${ }^{6}$ there is limited information on the places and types of visibility that should be restricted in order to gain maximum effects. For example, the role of tobacco specialist shops has not been previously clarified, as this type of shop is not common in the UK. There are however many shops in other European countries that are defined as primarily selling tobacco, but that also sell other products such as magazines and snacks. To our knowledge, PoS tobacco display bans usually exempt tobacconists, and in some cases small shops were initially exempted. ${ }^{11}$

In the Netherlands, PoS display bans have not been implemented, but will go into effect in supermarkets in 2020 and in small shops in 2022. Tobacconists will be exempt. Currently, tobacco product visibility is not restricted, and tobacco advertisement in and outside the building is allowed in tobacconists. ${ }^{15}$ This study aimed to map the internal and external visibility of tobacco products in Amsterdam among different types of retailers. We aimed to determine to what extent tobacco products are visible inside and outside of tobacco retailers in Amsterdam, how tobacco retailers are geographically distributed and to what extent the visibility varies between different types of retailers. With this information we contribute to understanding the potential impact of removing PoS displays on reducing the visibility of tobacco in the retail environment.

\section{METHODS}

\section{Study setting}

Data were collected in two districts in Amsterdam. To increase the variability of different parts of Amsterdam, we chose districts with a low and high property value. District 1 had a property value between $€ 3500$ and $€ 6000$ per $\mathrm{m}^{2}$, and district 2 had a property value ranging between $€ 1500$ and $€ 3500$ per $\mathrm{m}^{2}$. Both districts are situated in residential areas. See online supplementary appendix table 1 for detailed information per district. The results are presented separately for the two districts. Data collection was conducted in April-May 2017.
Patient and public involvement

No patients or public were involved in the study.

\section{Data collection}

Observational and locational data were collected for all tobacco retailers within the selected districts by walking through all streets within the districts. As the Netherlands does not have a tobacco retailer register, a researcher visited all supermarkets, convenience stores, snack bars, pubs/cafes, gas stations, coffee shops (defined as a store where marijuana and hash are sold), drug stores, telephone communications store (telecom), casinos, office supply stores and tobacconists in the selected districts. All the previously mentioned stores were identified as tobacco retailers if they sold tobacco. These represent the most common tobacco retailers in the Netherlands.

An observational checklist was developed based on the Scottish Determining the Impact of Smoking Point of Sale Legislation Among Youth (DISPLAY) study (see online supplementary appendix table 2) ${ }^{6}{ }^{16}$ The Standardized Tobacco Assessment for Retail Settings questionnaire was additionally used as a foundation for the current study. We adapted the DISPLAY checklist on three points, following extensive discussion among coauthors on the definitions, applicability and usability of the checklist in the Dutch context. First, we did not use 5-point scales for each item, but merely observed whether the items were present or not. This made the observation less ambiguous to define, and more straightforward to interpret. Second, we added items on vending machines, as these are important within the Dutch context. Third, we added an item that distinguished between types of retailers.

Our checklist included 18 items about the internal and external visibility of tobacco. It was pilot-tested in a random selection of streets in a neighbourhood in Amsterdam which were not included in the final study area. The primary aim of the pilot was to test the checklist and the practicalities of data collection. Two researchers tested the checklist, both applying the same data collection protocol, and no discrepancies were found between researchers' results.

Following the pilot study, data collection was started. One researcher collected data for all tobacco retailers in each neighbourhood by systematically walking through each street. The researcher visited each retailer and observed the characteristics on the checklist. If it was unclear whether tobacco was sold, the observer asked the vendor whether it was possible to buy cigarettes. The checklist was completed directly outside of each tobacco retailer. In addition to the observational checklist, the GPS coordinates were registered using a portable GPS right outside each tobacco retailer. The observational and locational data were linked within a Geographic Information System (ARCGIS 10.4).

\section{Variables}

In order to describe tobacco visibility, the following variables were included: visibility of graphic or textual 
warning on packs, visibility of tobacco packs, visibility of tobacco packs at eye level (height $1.60-1.80 \mathrm{~m}$ ), visibility of advertisement for tobacco brands, types of advertisement for tobacco brands (not applicable, sign, television screen, multiple forms of advertisement) and the placement of advertisement (not applicable, shop window, on the way to the main counter). All variables were observed internally (inside the store) and externally (outside the store), with the exception of the visibility of graphic warning/textual warning on packs which was always observed internally.

We classified retailers as having internal visibility of tobacco products if they scored positive on at least one of the following variables: visibility of tobacco packs, visibility of graphic warnings and visibility of advertisement of tobacco. Tobacco packs were visible internally if the researcher saw the packs when walking from the retailer entrance to the main counter. Retailers had external visibility if they scored positive on at least one of the two variables: visibility of tobacco packs and visibility of advertisement.

Type of retailer was categorised into four types: supermarkets, hospitality sector (pub/café, coffee shop, snack bar and casino), tobacconists (defined as stores that sell at least 90 brand varieties of tobacco products, ${ }^{15}$ but that may also sell magazines, snacks and often contain a postal service) and other (convenience store, office supply store, gas station, drug store and telecom).

\section{Data analysis}

To describe the geographical distribution of retailers and their visibility, the internal and external visibility of tobacco products were mapped using Geographic Information System (GIS). Two maps were created, one for each district, which distinguished retailers with internal visibility only, internal and external visibility or no visibility. The density of the visibility of tobacco products or advertisement was quantified as the number of retailers with internal and external visibility, respectively, of tobacco products or advertisement per square kilometre and in number of retailers with visibility per 1000 inhabitants. Data on the number of inhabitants per district were obtained from the population registry in Amsterdam. ${ }^{17}$ Both districts were combined in these measurements, and calculations were stratified by store type. ${ }^{6}$

\section{RESULTS}

A total of 82 retailers were observed within the selected neighbourhoods (see online supplementary appendix table 3). Most retailers were from the hospitality sector $(n=29)$, followed by supermarkets $(n=19)$, retailers categorised under 'other' $(\mathrm{n}=18)$ and tobacconists $(\mathrm{n}=16)$. Thirty-one per cent of products were sold through vending machines, primarily within the hospitality sector $(83 \%)$.

Figure 1 shows a map per district highlighting all tobacco retailers with their respective visibility. In both districts, tobacco retailers are predominantly clustered near main traffic roads, closely together. In district 1 , a main road had six retailers with external visibility over a distance of $1000 \mathrm{~m}$. Many retailers are located on street corners and in the vicinity of public transportation.

Table 1 shows the number of retailers with internal and external tobacco visibility per $\mathrm{km}^{2}$ and per 1000 inhabitants. We found approximately four retailers per $\mathrm{km}^{2}$ exhibiting only internal visibility of tobacco products and about five retailers per $\mathrm{km}^{2}$ with both internal and external visibility. There were 0.31 retailers per 1000 inhabitants with only internal visibility of tobacco and 0.42 retailers per 1000 inhabitants with internal and external visibility of tobacco products. Internal visibility was high in the hospitality sector, with 2.07 retailers per $\mathrm{km}^{2}$ with internal visibility compared with 0.69 supermarkets per $\mathrm{km}^{2}$ and 0.92 per $\mathrm{km}^{2}$ for other retailers. Tobacconists had the highest internal and external visibility, with about two retailers per $\mathrm{km}^{2}$ and 0.15 per 1000 inhabitants, whereas retailers in the hospitality had the lowest with 0.92 retailers per $\mathrm{km}^{2}$ and 0.08 per 1000 inhabitants.

Table 2 provides an overview of the internal and external visibility of tobacco products among all retailers and per type of retailer. Overall, $92 \%$ of retailers showed some form of internal visibility and $52 \%$ had external visibility. Internally, tobacco packs were visible in $82 \%$ of retailers and $62 \%$ were visible at eye-level of the customer. Four supermarkets, nine cafes and two snack bars did not have visible tobacco packs inside (18\%). The four supermarkets were chains that have voluntarily removed displays of tobacco. Tobacco in the nine cafes and two snack bars was sold through vending machines. Vending machines that were often placed near the toilets in cafes and therefore not visible when walking from the retailer entrance to the main counter. Sixteen per cent of visible tobacco packs did not have visible graphic warning signs. In addition to tobacco products, $22 \%$ of retailers had some form of advertisement (signs, television screens or multiple forms). Tobacco packs were also visible externally in $49 \%$ of retailers and visible at eye-level in $40 \%$. Moreover, $21 \%$ of retailers had advertisements of tobacco products, and all were visible at the shop window.

Table 2 presents visibility by type of retailer. Tobacco products were visible inside all tobacconists and 'other' retailers. In supermarkets and the hospitality sector, $79 \%$ and $62 \%$ of retailers, respectively, have visible packs on display. Packs are mostly visible at eye-level in supermarkets, tobacconists and other retailers, whereas packs are not visible at eye-level in the hospitality sector, due to the large share of sales through vending machines. Graphic warning sign labels were not visible in $21 \%$ of supermarkets, $28 \%$ of the hospitality sector and $6 \%$ of other retailers. Advertisement of tobacco brands was always visible among tobacconists, but no internal display of advertisements was found in supermarkets. Advertisement was rarely seen in the hospitality sector and 'other' retailers. Tobacconists had advertisements in the form of signs $(n=3)$, television screens $(n=2)$ and a combination 


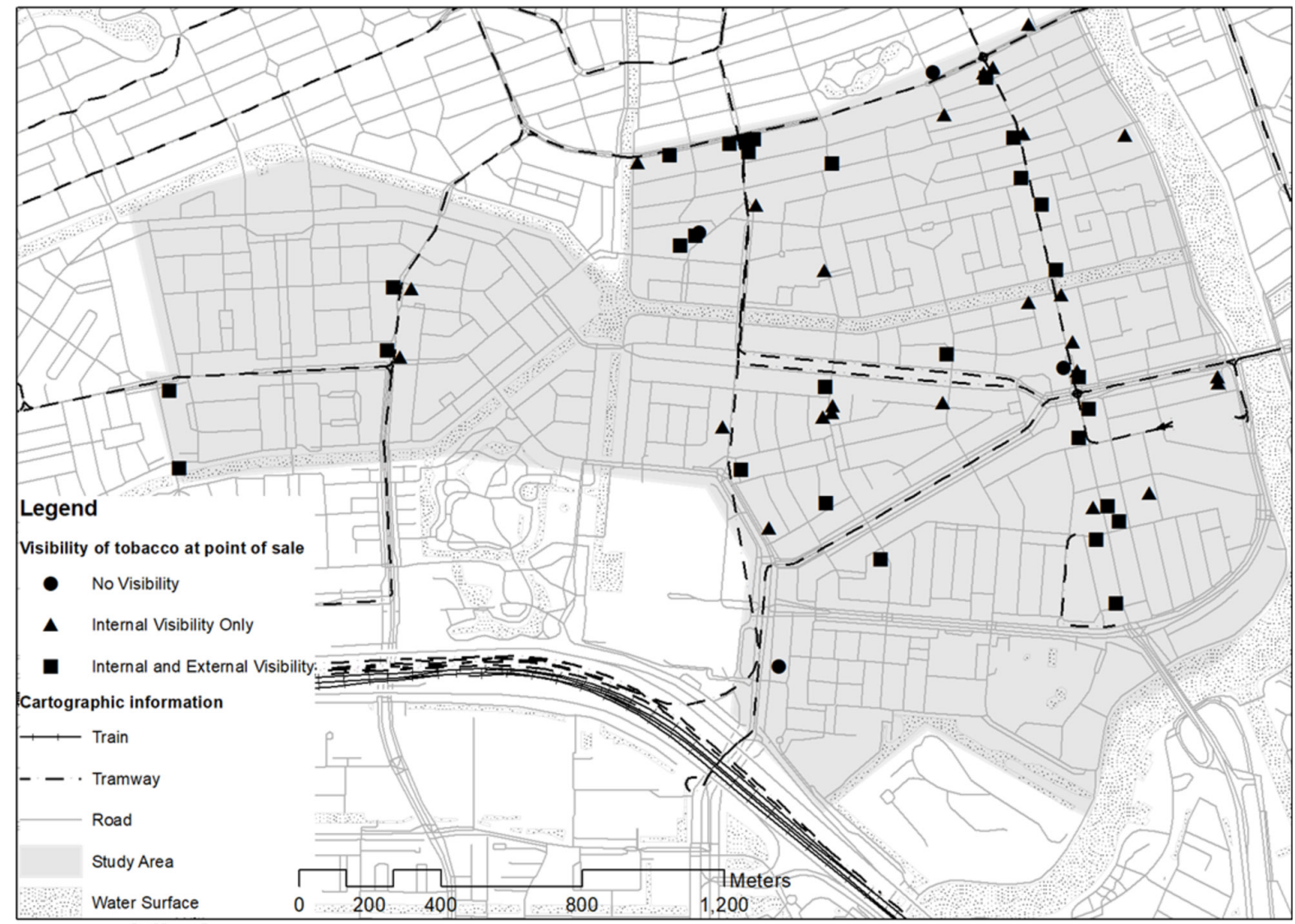

\section{A. Map of district 1.}

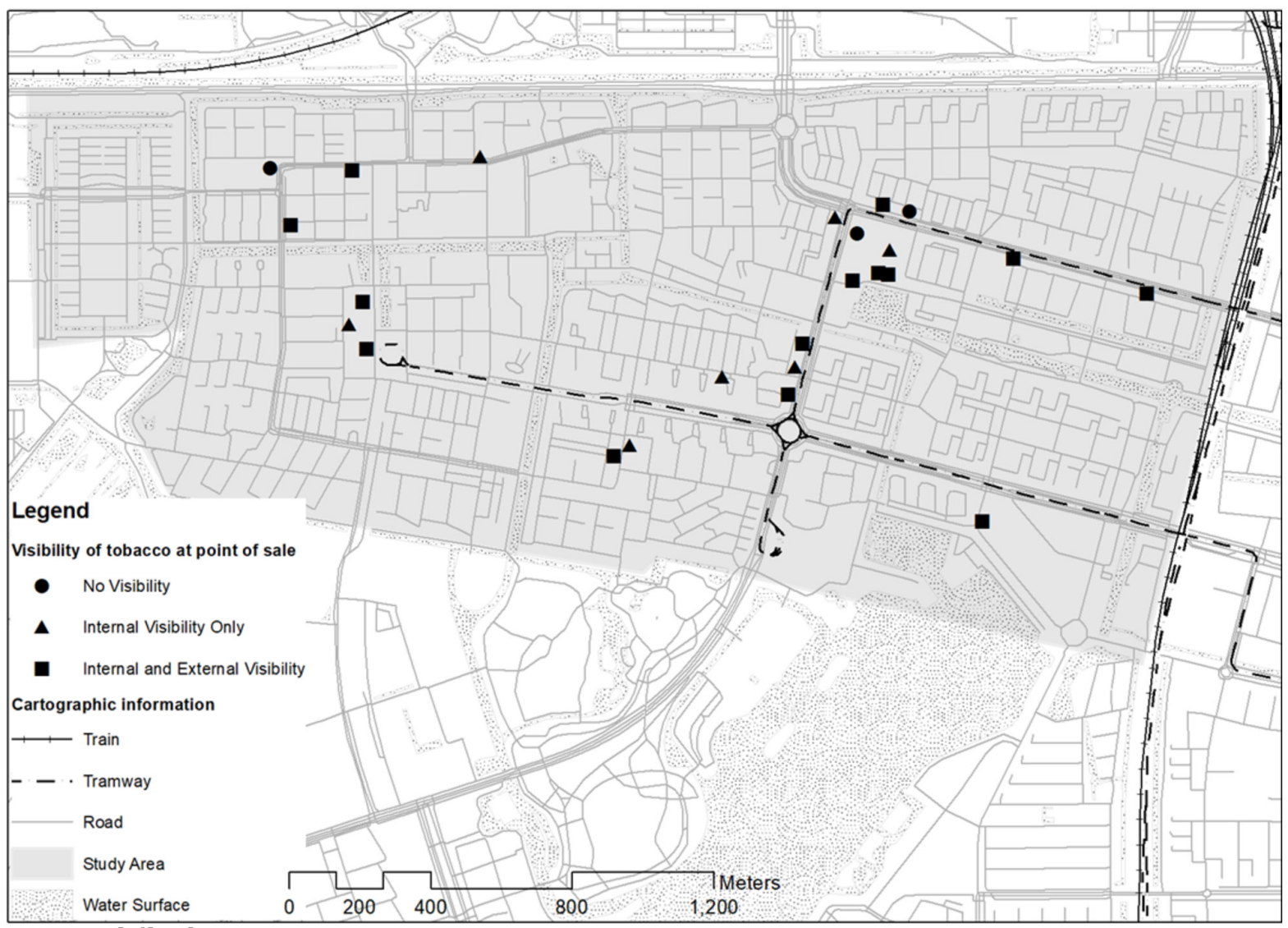

B. Map of district 2.

Figure 1 Map of each district presenting the visibility of tobacco at the points of sale. The existing road network maps were obtained from Environmental Systems Research Institute (ESRI) Nederland, an open-source dataset. ${ }^{26}$ 
Table 1 Number of visible outlets per venue

\begin{tabular}{|c|c|c|c|c|c|}
\hline & Total & Supermarkets & Hospitality & Tobacconists & Other \\
\hline \multicolumn{6}{|c|}{ Number visible outlets per $\mathrm{km}^{2}$} \\
\hline Internal-only & 3.69 & 0.69 & 2.07 & 0 & 0.92 \\
\hline \multicolumn{6}{|c|}{ Number visible outlets per 1000 inhabitants } \\
\hline Internal-only & 0.31 & 0.06 & 0.17 & 0 & 0.08 \\
\hline
\end{tabular}

${ }^{*}$ All retailers with external visibility also had internal visibility.

of different types of advertisement $(n=11)$. The placement of advertisements was always on the way to the main counter. Overall, internal visibility was highest in tobacconists and retailers categorised under other (100\%), followed by the hospitality sector $(93 \%)$ and supermarkets $(79 \%)$.

Across types of retailers, external visibility was highest in tobacconists $(100 \%)$, followed by retailers categorised under other $(56 \%)$, supermarkets $(47 \%)$ and the hospitality industry (28\%). Tobacconists showed high levels of external visibility of tobacco packs at eye-level $(88 \%)$ and external visibility of advertisement (100\%). Tobacco packs were externally visible in $47 \%$ of supermarkets and $50 \%$ of 'other' retailers. Packs were least visible from the outside in the hospitality sector $(28 \%)$. External visibility of advertisements in retailers other than tobacconists was rare $(n=1)$.

\section{DISCUSSION}

\section{Key findings}

Visibility of tobacco products is high among all types of retailers in the Netherlands. Ninety-two per cent of retailers have tobacco products visible inside and half have tobacco products visible from outside the store. These visible tobacco retailers are primarily clustered around highly accessible, main traffic roads. The internal and external visibility of tobacco products was highest among tobacconists and those categorised under 'other' retailers (snack bars, coffee shops, office supply stores and drug stores). External visibility was lowest among retailers in the hospitality industry $(28 \%)$, as most tobacco products were sold through vending machines inside the establishments $(83 \%)$.

\section{Potential limitations}

This study is limited by a small sample size and selection of a limited number of settings which may limit the generalisability of the study results. Our findings may not be generalisable to other countries or European cities, and more research is needed to compare our findings with other European contexts. Nevertheless, the types of retailers identified in this study are common points of sale throughout the Netherlands. The visibility of these retailers may be generalisable to other residential areas of Dutch cities because chain stores are likely to have to conform to the same tobacco display regulations. Larger studies are needed to map the PoS displays in the Netherlands at large.

We only had one observer collecting data. Although this means that there was no interobserver bias, the quality of the data may be limited by the attentiveness and interpretation of one researcher. However, we reduced subjectivity by using clear answer categories in the checklist, and the pilot study showed a high level of interobserver agreement. As one observer made all observations, comparisons between shop types are valid.

Some tobacco retailers may not have been included in the study if they were missed during the observation. We made an initial selection of potential retailers and only observed those types. Although the systematic approach of data collection minimised the risk, other types of retailers or unrecognisable stores may have been missed.

\section{Interpretation of results}

Our findings show that tobacconists and retailers categorised under 'other' (snack bars, coffee shops, office supply stores and drug stores) had the highest level of visibility of tobacco products and advertisements. Although we have not directly measured exposure to individuals, previous studies found that youth most frequently visit confectioners, tobacconists and newsagents, followed by small/ corner shops and supermarkets. ${ }^{6}$ Confectioners and newsagents are included under our 'other' category. In addition, smoking youth often buy cigarettes from corner shops, kiosks and gas stations. ${ }^{18-20}$ The high visibility that we found in these shop types is in line with previous studies. A study in Scotland found that $80 \%$ of those visiting such shops noticed tobacco products. ${ }^{6}$ Furthermore, a study in California found that there were 3.4 times more cigarette ads in stores which youth frequently visit. $^{21}$ If these exposure data apply to the Netherlands, Dutch youth are exposed to highly visible tobacco products, especially in tobacconists and smaller retailers. This would be associated with cigarette brand awareness ${ }^{8}$ and smoking susceptibility. ${ }^{7}$ Nevertheless, further research is needed to determine the actual exposure of young people to tobacco products in the Netherlands and in other European countries.

In the Netherlands, a PoS display ban will go into effect in supermarkets in 2020 and among all remaining points 
Table 2 Internal and external visibility of tobacco products

\begin{tabular}{|c|c|c|c|c|c|}
\hline Visibility measure & $\begin{array}{l}\text { Total outlets } \\
\mathrm{n}=82\end{array}$ & $\begin{array}{l}\text { Supermarkets } \\
\mathrm{n}=19\end{array}$ & $\begin{array}{l}\text { Hospitality sector } \\
n=29\end{array}$ & $\begin{array}{l}\text { Tobacconists } \\
\mathrm{n}=16\end{array}$ & $\begin{array}{l}\text { Other } \\
\mathrm{n}=18\end{array}$ \\
\hline \multicolumn{6}{|l|}{ Internal visibility, n (\%) } \\
\hline Overall internal visibility* & 75 (91.5) & 15 (78.9) & $26(89.7)$ & $16(100)$ & $18(100)$ \\
\hline \multicolumn{6}{|l|}{ Visibility of tobacco packs } \\
\hline Yes & $67(81.7)$ & $15(78.9)$ & $18(62.1)$ & $16(100)$ & $18(100)$ \\
\hline \multicolumn{6}{|l|}{$\begin{array}{l}\text { Visibility of tobacco packs at } \\
\text { eye-level }\end{array}$} \\
\hline Yes & $51(62.2)$ & $13(68.4)$ & $8(27.6)$ & $16(100)$ & $14(77.8)$ \\
\hline \multicolumn{6}{|l|}{ Visibility of graphic warning } \\
\hline Yes & $69(84.1)$ & 15 (78.9) & $21(72.4)$ & $16(100)$ & $17(94.4)$ \\
\hline \multicolumn{6}{|l|}{ Visibility advertisement } \\
\hline Yes & $18(22)$ & - & $1(3.4)$ & $16(100)$ & $2(11.1)$ \\
\hline \multicolumn{6}{|l|}{ Types of advertisement } \\
\hline Not applicable & $64(78)$ & $19(100)$ & $29(100)$ & - & $16(88.9)$ \\
\hline Sign & $3(3.7)$ & - & - & $3(18.8)$ & - \\
\hline Television screen & $3(3.7)$ & - & - & $2(12.5)$ & $1(5.6)$ \\
\hline $\begin{array}{l}\text { Multiple forms of } \\
\text { advertisement }\end{array}$ & $12(14.6)$ & - & - & $11(68.8)$ & $1(5.6)$ \\
\hline \multicolumn{6}{|l|}{ Placement advertisement } \\
\hline Not applicable & $64(78)$ & $19(100)$ & $29(100)$ & - & $16(88.9)$ \\
\hline On way to main counter & $18(22)$ & - & - & $16(100)$ & $2(11.1)$ \\
\hline \multicolumn{6}{|l|}{ External visibility } \\
\hline Overall external visibility† & $43(52.4)$ & $9(47.4)$ & $8(27.6)$ & $16(100)$ & $10(55.6)$ \\
\hline \multicolumn{6}{|l|}{ Visibility of tobacco packs } \\
\hline Yes & $40(48.8)$ & $9(47.4)$ & $8(27.6)$ & $14(87.5)$ & $9(50)$ \\
\hline \multicolumn{6}{|l|}{$\begin{array}{l}\text { Visibility of tobacco packs at } \\
\text { eye-level }\end{array}$} \\
\hline Yes & $33(40.2)$ & $7(36.8)$ & $4(13.8)$ & $14(87.5)$ & $8(44.4)$ \\
\hline \multicolumn{6}{|l|}{ Visibility advertisement } \\
\hline Yes & $17(20.7)$ & - & - & $16(100)$ & $1(5.6)$ \\
\hline \multicolumn{6}{|l|}{ Type of advertisement } \\
\hline Not applicable & $65(79.3)$ & $19(100)$ & $29(100)$ & - & $17(94.4)$ \\
\hline Sign & $4(4.9)$ & - & - & $3(18.8)$ & $1(5.6)$ \\
\hline Television screen & $10(12.2)$ & - & - & $10(62.5)$ & - \\
\hline $\begin{array}{l}\text { Multiple forms of } \\
\text { advertisement }\end{array}$ & $3(3.7)$ & - & - & $3(18.8)$ & - \\
\hline \multicolumn{6}{|l|}{ Placement advertisement } \\
\hline Not applicable & 65 (79.3) & $19(100)$ & $29(100)$ & - & $17(94.4)$ \\
\hline Shop window & $17(20.7)$ & - & - & $16(100)$ & $1(5.6)$ \\
\hline
\end{tabular}

${ }^{*}$ Overall internal visibility: retailers that had at least one of the following variables: visibility of tobacco packs, visibility of graphic warnings and visibility of advertisement of tobacco.

†Overall external visibility: retailers that had at least one of the two variables: visibility of tobacco packs and visibility of advertisement.

in 2022. ${ }^{22} 23$ Shops selling only tobacco and tobacco accessories will be exempt from this ban which we estimate to represent $62 \%$ of the tobacconists in our sample. Therefore, tobacconists will continue to be highly visible. In order to optimally limit the visibility of tobacco products and tobacco advertisement, display bans would need to be comprehensive, encompassing all retailers and be accompanied by a strict advertising ban.

To our knowledge, no studies have examined the visibility of tobacco products in vending machines. We 
found that almost $83 \%$ of tobacco products in the hospitality industry were visible through vending machines. Tobacco vending machines were visible indoors, but not from outside stores nor at the eye-level of the customer. Nevertheless, vending machines are primarily located near bathrooms, an area which most customers often pass. This implies that exposure to tobacco products in vending machines may be high. An American study found that young adults initiating or experimenting with tobacco were less likely to smoke in localities with a complete vending machine ban compared with localities with a partial ban which allowed vending machines in adult facilities such as bars. ${ }^{24}$ Vending machines have been banned in several European countries including the UK, Finland, France and Iceland, and will probably be banned in the Netherlands in $2022 .{ }^{25}$

As a large part of Europe has no restrictions on tobacco PoS displays, it would be of great interest to compare tobacco visibility and $\mathrm{PoS}$ advertisement in multiple European settings. Such a study provides the opportunity to apply the developed checklist on an international scale, with specific interest to countries where exposure could be measured before and after the implementation of new PoS display bans.

\section{CONCLUSION}

This study in Amsterdam shows that visibility of tobacco products inside and outside retailers was still high in all types of retailers, including retailers that are commonly visited by youth. In such a case, the visibility for young people of tobacco products and advertisements can only be effectively addressed by a PoS display ban that covers all retailers and vending machines.

Acknowledgements The authors would like to thank Sanne Heijndijk at the Dutch alliance for a smoke-free society, for her input on the legal situation in the Netherlands.

Contributors PAWN, MAGK, EMV and AEK designed the study. All authors (PAWN, MAGK, AC, MCW, EMV, AEK) contributed to the development of the observation checklist. AC and PAWN pilot-tested the observation checklist and AC collected the data. PAWN and MAGK carried out the data analysis and drafted the manuscript. All authors contributed to the writing of the manuscript and approved the final manuscript.

Funding This study is part of the SILNE-R project which received funding from the European Commission (EC), Horizon2020 program, Call PHC6-2014, under Grant Agreement n635056.

Competing interests None declared.

Patient consent Not required.

Provenance and peer review Not commissioned; externally peer reviewed.

Data sharing statement Data can be made available on reasonable request to the corresponding author, if a detailed research plan is submitted that contributes to the aim to prevent smoking.

Open access This is an open access article distributed in accordance with the Creative Commons Attribution Non Commercial (CC BY-NC 4.0) license, which permits others to distribute, remix, adapt, build upon this work non-commercially, and license their derivative works on different terms, provided the original work is properly cited, appropriate credit is given, any changes made indicated, and the use is non-commercial. See: http://creativecommons.org/licenses/by-nc/4.0/.

\section{REFERENCES}

1. Joossens LRM. Association of European Cancer Leagues. The Tobacco Control Scale 2016 in Europe, 2017.

2. Organization WH. European Tobacco Control Status Report 2014, 2014.

3. Organization WH. Evidence brief Tobacco point- of- sale display bans, 2017

4. Dewhirst T. POP goes the power wall? Taking aim at tobacco promotional strategies utilised at retail. Tob Control 2004;13:209-10.

5. Feighery EC, Ribisl KM, Clark PI, et al. How tobacco companies ensure prime placement of their advertising and products in stores: interviews with retailers about tobacco company incentive programmes. Tob Control 2003;12:184-8.

6. Stead M, Eadie D, MacKintosh AM, et al. Young people's exposure to point-of-sale tobacco products and promotions. Public Health 2016;136:48-56.

7. Spanopoulos D, Britton J, McNeill A, et al. Tobacco display and brand communication at the point of sale: implications for adolescent smoking behaviour. Tob Control 2014;23.

8. van der Sluijs W, Haseen F, Miller M, et al. "It looks like an adult sweetie shop": Point-of-sale tobacco display exposure and brand awareness in scottish secondary school students. Nicotine Tob Res 2016;18:1981-8.

9. Mackintosh AM, Moodie C, Hastings G. The association between point-of-sale displays and youth smoking susceptibility. Nicotine Tob Res 2012;14:616-20.

10. Pollay RW. More than meets the eye: on the importance of retail cigarette merchandising. Tob Control 2007;16:270-4.

11. Monshouwer K, Verdurmen J, Ketelaars T, et al. Points of sale of tobacco products: Synthesis of scientific and practice based knowledge on the impact of reducing the number of points of sale and restrictions on tobacco product displays. Trimbos-Instituut 2014

12. Li L, Borland R, Fong GT, et al. Impact of point-of-sale tobacco display bans: findings from the international tobacco control four country survey. Health Educ Res 2013;28:898-910.

13. Edwards R, Ajmal A, Healey B, et al. Impact of removing point-ofsale tobacco displays: data from a New Zealand youth survey. Tob Control 2017;26:392-8.

14. Dunlop S, Kite J, Grunseit AC, et al. Out of sight and out of mind? evaluating the impact of point-of-sale tobacco display bans on smoking-related beliefs and behaviors in a sample of australian adolescents and young adults. Nicotine Tob Res 2015;17:761-8.

15. Overheid.nl, 2017. Tabaks- en rookwarenwet http://wetten.overheid. nl/BWBR0004302/2017-07-01\#Paragraaf3.

16. Henriksen L, Ribisl KM, Rogers T, et al. Standardized Tobacco Assessment for Retail Settings (STARS): dissemination and implementation research. Tob Control 2016;25:i67-i74.

17. Gemeente Amsterdam. Onderzoek, informatie en statistiek. https:// www.ois.amsterdam.nl/feiten-en-cijfers/.

18. Rimpelä $\mathrm{AH}$, Rainio SU. The effectiveness of tobacco sales ban to minors: the case of Finland. Tob Control 2004;13:167-74.

19. DiFranza JR, Coleman M. Sources of tobacco for youths in communities with strong enforcement of youth access laws. Tob Control 2001;10:323-8.

20. Borland T, Amos A. An exploratory study of the perceived impact of raising the age of cigarette purchase on young smokers in Scotland. Public Health 2009;123:673-9.

21. Henriksen L, Feighery EC, Schleicher NC, et al. Reaching youth at the point of sale: cigarette marketing is more prevalent in stores where adolescents shop frequently. Tob Control 2004;13:315-8.

22. Overheid.nl, 2017. Kamerstuk: tweede kamer der staten-generaal https://zoek.officielebekendmakingen.nl/kst-32011-59.html? zoekcriteria=\%3fzkt\%3dEenvoudig\%26pst\%3d\%26vrt\% 3ddisplay\%2bban\%26zkd\%3dlnDeGeheleText\%26dpr\% 3dAfgelopenDag\%26sdt\%3dDatumBrief\%26ap\%3d\%26pnr\%3d1\% 26rpp\%3d10\&resultIndex=2\&sorttype=1\&sortorder=4.

23. Ministerie van Volksgezondheid WeS. Besluit houdende wijziging van het Tabaks- en rookwarenbesluit. 2017 https://www. internetconsultatie.nl/besluit_houdende_wijziging_van_het_tabaks_ en_rookwarenbesluit.

24. Vuolo M, Kelly BC, Kadowaki J. Impact of total vending machine restrictions on us young adult smoking. Nicotine Tob Res 2016;18:2092-9.

25. Ministerie van Volksgezondheid WeS. Tabak uit het zicht, automaat verdwijnt ministerie van algemene zaken. 2017 https://www. rijksoverheid.nl/actueel/nieuws/2017/07/05/tabak-uit-het-zichtautomaat-verdwijnt.

26. Nederland e. Datasets: esri nederland. 2017 http://www.esri.nl/ producten/content/datasets. 